\title{
LA INSOSTENIBLE SOLEDAD DEL LECTOR. LA LECTURA COMO TRABAJO INDIVIDUAL Y COLECTIVO
}

\author{
THE UNSUSTAINABLE SOLITUDE OF THE READER. READING \\ AS INDIVIDUAL AND COLLECTIVE WORK
}

\author{
Mirko LAMPIS \\ Universidad Constantino el Filósofo de Nitra (República Eslovaca) \\ mlampis@ukf.sk
}

Resumen: El objetivo de este trabajo es estudiar la lectura en tanto que experiencia individual (yo leo) y, a la vez, práctica cultural (todos leemos solo porque y en la medida en que integramos una cultura escribiente y leyente). Por lo tanto, tras ofrecer una definición general de la noción de lectura (apartado 1) y examinar algunas cuestiones pertinentes relativas a la historia de la lectura (apartado 2), trataremos los siguientes temas (apartado 3): la enseñanza y el aprendizaje del leer y de la lectura, los procesos de lectura orientada y la comprensión de lo leído.

Palabras clave: Lectura. Escritura. Cultura.

Abstract: The goal of this paper is to study the reading as individual experience (I read) and, at the same time, cultural practice (we all read only because and insofar as we integrate a writing and reading culture). So, after giving a general definition of the notion of reading (section 1) and after examining some pertinent questions concerning the history of reading (section 2), we will address the following topics (section 3): the 
teaching and learning to read and reading, the oriented reading processes and the reading understanding.

Key Words: Reading. Writing. Culture.

\section{HABLANDO DE LECTURAS (Y ESCRITURAS)}

Quien no lee, a los 70 años habrá vivido una sola vida, ;la propia! Quien lee, habrá vivido 5000 años: Estaba cuando Caín mató a Abel, cuando Renzo se casó con Lucía, cuando Leopardi admiraba el infinito... Porque la lectura es la inmortalidad hacia atrás.

Umberto Eco

Llegada la tarde, me vuelvo a casa, y entro en mi escritorio; $y$ en el umbral me despojo de aquella vestimenta cotidiana,

llena de fango y lodo, y me pongo paños reales y curiales; $y$ así revestido condignamente, entro en las antiguas cortes de los antiguos hombres; donde, recibido por ellos amablemente, pasto de aquel alimento que solo es mío y para el que yo nací.

Nicolás Maquiavelo

No olvidemos una verdad de Pero Grullo: que las obras literarias han sido escritas para un ser tierno, inocentísimo 
y profundamente interesante: el lector.

Dámaso Alonso

Cuanto menos se lee, más daño hace lo que se lee. Miguel de Unamuno

Como sabemos, el verbo leer se suele emplear, bien de forma metafórica, bien al amparo de su etimología ${ }^{1}$, como sinónimo de interpretar, descifrar, descodificar. Por ejemplo, en expresiones como "leer una situación", "leer el tiempo", "leer un cuadro", "leer una expresión”, "leer el gran libro del mundo"; y aún: "leer un esquema", "leer un diagrama", "leer una partitura musical", "leer una fórmula matemática". Aquí, sin embargo, no nos ocuparemos de tales usos, sino solo de la lectura en su acepción hoy en día más corriente, es decir, como actividad que consiste en dedicarse a - o en dirigir la atención hacia-las expresiones que integran un texto lingüistico escrito, reconociéndolas y organizándolas en conjuntos significantes (precisamente lo que está Ud. haciendo en este momento). En otras palabras, la acepción primera del vocablo leer tal y como lo recogen los modernos diccionarios de la lengua:

- "Pasar la vista [o el tacto, cabría añadir] por lo escrito o impreso comprendiendo la significación de los caracteres empleados" (Diccionario de la Real Academia Española).

- "Interpretar mentalmente o traduciéndolos en sonidos los signos de un escrito" (Diccionario de Uso del Español).

- "Descifrar, en general sirviéndose de la vista, mentalmente o enunciándolo en voz alta, el valor fónico de los signos de la escritura" (Diccionario del Español Actual)2.

\footnotetext{
${ }^{1}$ Del latín lěgo, is, lēgi, lectum, ĕre: 'recoger', 'extraer', 'elegir'.

${ }^{2}$ Nótese que las definiciones del DUE y del DEA, a diferencia de la del DRAE, no implican en el acto de lectura la comprensión del significado de lo que se lee. Resulta también pertinente, al respecto, la definición propuesta por Greimas y Courtés en su Diccionario
} 
Nuestro objetivo es, en suma, estudiar la lectura en tanto que interacción con textos escritos en algún idioma. Pero no cualquier interacción, ya que nos centraremos sobre todo en ese tipo de lectura que podríamos definir como "no analítica" (o incluso "ingenua"); aquella lectura, en otras palabras, que sigue y se entrega al texto (y a sus azares y contingencias), sin buscar "estructuras profundas" ni "significaciones originales" y limitando, por lo tanto, los "reenvíos y saltos, anticipaciones y controles hacia atrás" que caracterizan, como dijera Eco (1979: 175), las representaciones teóricas de los niveles profundos de cooperación. Y tampoco con cualquier tipo de texto, dado que nos referiremos principalmente a textos informativos y literarios concebidos, producidos y divulgados según el formato del "libro" (rollo, códice, e-book) o del "fascículo" (periódico, revista, folleto), sin apenas considerar escritos de otro tipo (eslóganes, instrucciones, etiquetas, rótulos, etc.). Y tampoco en cualquier idioma, puesto que solo nos ocuparemos de escrituras alfabéticas, es decir, sistemas de notación gráfica que tratan de representar los sonidos articulados en el habla ${ }^{3}$.

(1979: 235): "En una primera aproximación, se entiende por lectura el proceso de reconocimiento de los grafemas (o letras) y de su concatenación, que tiene como resultado transformar una hoja adornada con símbolos dibujados en plano de expresión de un texto. Por extensión, el término lectura se emplea al hablar de otras sustancias de expresión distintas del grafismo: la lectura táctil es practicada por los ciegos que se valen de libros impresos en relieve, la lectura óptica designa el desciframiento de los caracteres escritos por la computadora, etc."; sin embargo, parece necesario, en segunda instancia, recuperar también la dimensión semántica y pragmática de la lectura, ya que esta "es, ante todo - y esencialmente-, una semiosis, una actividad primordial que tiene por efecto correlacionar un contenido con una expresión dada y transformar una cadena de la expresión en una sintagmática de signos. De ello se desprende, en seguida, que tal prestación presupone una competencia del lector, comparable, aunque no necesariamente idéntica, con la del productor del texto".

${ }^{3}$ Para que no haya dudas acerca de lo que entendemos por "habla", "oralidad" y "escritura", vuelvo a proponer las siguientes dos definiciones: "Se define como 'lengua oral' y como 'habla' la comunicación mediante expresiones producidas gracias a la actividad de los órganos respiratorios (pulmones, tráquea, etc.), fonatorios (laringe, cavidad bucal, etc.) y articulatorios (lengua, labios, etc.), y como 'oralidad' el conjunto de los hábitos $\mathrm{y}$ tradiciones que se derivan de (y regulan) esta forma de comunicación. Se define como 
Es importante reconocer, de entrada, que la lectura, aun en el significado restringido que aquí le damos y con todas las limitaciones indicadas, no es una actividad lineal, sino compleja y complejamente arraigada en lo cultural, y que por lo tanto puede ser presentada y descrita de diferentes maneras. Sirva de ejemplo la siguiente lista de Barthes y Compagnon (1979: 176-178), que integramos con algunas observaciones personales:

i) "leer es una técnica": técnica de descodificación e interpretación ( $\mathrm{o}$, si se quiere, de deconstrucción y reconstrucción) del discurso escrito; presupone, por lo tanto, el aprendizaje de una serie de convenciones y operaciones sobre códigos, estructuras y funciones expresivas (lingüísticas y gráficas) y una pedagogía, un sistema de enseñanza de tales operaciones y convenciones; esta pedagogía cambia con el tiempo, así como cambian las tecnologías implicadas en el proceso ${ }^{4}$;

ii) "leer es una práctica social": durante miles de años la escritura y el acceso al documento escrito (la lectura) han sido operaciones de discriminación social, ya que los analfabetos quedaban sistemáticamente excluidos de la gestión activa del misterio revelado, del poder y de la "alta" cultura; podemos añadir que hoy en día, a pesar de una alfabetización extendida (o precisa-

\footnotetext{
'lengua escrita' y como 'escritura' la comunicación mediante expresiones gráficas (signos trazados sobre una superficie y reconocibles a la vista o al tacto) que representan (están por) las expresiones orales y reproducen su organización" (Lampis, 2013: 46, 49).

${ }^{4}$ En opinión de Sini, la escritura alfabética constituiría "la primera 'técnica' en el sentido performativo del término: un mero instrumento para el uso del cual no es necesario conocer el aura ni la epopeya (escondidas y disueltas en la estilización). Competencia sin sabiduría. Ignorancia eficiente, 'cartesiana', en tanto que fruto de un adiestramiento práctico para el cual toda inteligencia 'media' es suficiente. Mera transmisión del significado a través de vestimentas convencionales y computacionales; pues el alfabeto es un algoritmo: subdivisión 'analítica' de la cinta fónica transpuesta en el cuerpo linealizado de las letras" (Sini, 2012: 37; la traducción es mía).
} 
mente a raíz de ella), la escasa actitud de lectura activa (¿crítica?) y la incapacidad o el desinterés para comprender (leer) las diferentes estrategias escritoras y divulgativas siguen contribuyendo a la discriminación y al encasillamiento sociales;

iii) "leer es una forma de gestualidad" (y mejor aún, de corporeidad): tanto la lectura pública como la lectura privada en voz alta o murmurada implican el control de la respiración y de la voz y la activación de diferentes partes del cuerpo (actio), desde una verdadera y propia recitación hasta un movimiento labial apenas perceptible; toda lectura comporta, además, un seguimiento y una exploración oculares (o táctiles), el mantenimiento de una postura corporal y, finalmente, cierto desgaste de tiempo y de energía; como también recuerdan Cavallo y Chartier (1995: VI), "la lectura es siempre una práctica encarnada en determinados gestos, espacios, hábitos" "5;

iv) "leer es una forma de sabiduría": la lectura da acceso al patrimonio cultural constituido por la tradición escrita y es, por ende, un medio para recuperar, actualizar, diferenciar y dinamizar el conocimiento; es ella misma, además, en tanto que

\footnotetext{
${ }^{5}$ El cuerpo, una vez más, se configura como el centro (de gravedad fenomenológica) de toda actividad semiósica, y no sólo porque se lee con el cuerpo, sino también porque se lee a través del cuerpo: "lo que hay ahí fuera", el mundo, para resumirlo con palabras de González de Ávila (2016: 636), "ha de ser entendido, en sus inicios, como un campo de fuerzas, de tensiones que generan en él actividad y movimiento. Poco a poco [...] el campo de fuerzas se configura en tanto campo de presencia en torno a nosotros, o más bien en torno a nuestro cuerpo, entidad ante la cual las tensiones se hacen presentes. El cuerpo no tarda en explorar el campo de presencia con los sentidos a fin de tomar posesión de él, y de convertirse después en instancia enunciativa que 'dice', por medio de la palabra (o del gesto), el campo de fuerzas-campo de presencia, atribuyendo paulatinamente significados a sus diferencias tensivas y haciendo de él un campo de discurso". Así pues, el cuerpo del lector, "o más bien ese verdadero cuerpo-lector, transido por la corriente del lenguaje, es capaz de adaptarse miméticamente a lo leído gracias a su equipamiento sensorial; y de rescatar, a partir de los indicios verbales diseminados en el texto figurativo, la experiencia de la presencia, la manifestación graduada y escalar del ser" (González de Ávila, 2016: 643).
} 
técnica, método, actividad organizada e inscrita en lo social, un sistema de saberes prácticos y hermenéuticos — si es válida esta distinción - que se transmiten y adquieren en diferentes grados y niveles;

v) "leer es un método": la lectura es un instrumento intelectual destinado a organizar y clasificar de un modo determinado los significados de un texto escrito; es en este sentido, me parece, en el que se puede hablar de lectura crítica, alegórica, psicológica, existencial, etc.

vi) "leer es una actividad voluptuosa": el placer, sensual e intelectual, de la lectura; placer que adquiere matices diferentes, creemos, según se considere la actividad lectora como una forma de entretenimiento, diversión o escape, una forma de comunión estética o mística o una forma de rememoración, aprendizaje o revelación; formas relacionadas, si bien se mira, con los principales objetivos que la tradición retórica clásica asignaba al discurso: delectāre, movēre o docēre (porque se puede experimentar placer tanto al ser deleitado como al ser con-movido e instruido, por no hablar de los otros pequeños placeres exquisitamente lectores: el olor y la textura del papel, superar el reto de una lectura difícil, dormirse en medio de una frase, la familiaridad con un autor conocido, comunicarse con el otro, reconocerse o mejor conocerse en él, etc.).

Dado semejante panorama, está claro que no podremos aquí estudiar la lectura en todas sus facetas fisiológicas, psicológicas, conductuales, epistémicas, estéticas, económicas, tecnológicas, etc. Lo que propongo es, entonces, centrarnos en la doble dimensión de la lectura en tanto que experiencia individual (yo leo) y, al mismo tiempo, práctica cultural (todos leemos solo porque y en la medida en que integramos una cultura escritora y lectora). Con particular atención a los siguientes tres temas (que desarrollaremos en el apartado 3): i) la enseñanza y el aprendizaje del leer y de la lectura; ii) los procesos de lectura orientada; iii) la comprensión 
de lo leído. Antes de dedicarnos a tales puntos, sin embargo, me gustaría examinar brevemente algunas cuestiones relativas a la historia de la lectura que me parecen particularmente interesantes en perspectiva semiótica.

\section{GÉNESIS, MODALIDADES HISTÓRICAS Y CONTROL}

La escritura, técnica de representación del discurso oral sobre un soporte duradero, apareció en lugares diferentes y según modalidades diferentes; por lo que sabemos, sendas formas de escritura fueron elaboradas en Sumeria hacia el 3200/3000 a.C., en Egipto hacia el 3100/3000 a.C., en India hacia el 2500 a.C. y en China hacia el 2000 a.C.; la escritura alfabética apareció más tarde, alrededor del 1400 a.C., en las costas del Mediterráneo oriental y del Mar Rojo (Gilmont, 2004: 37-39) ${ }^{6}$.

En cuanto al porqué de la aparición de la escritura, se suele indicar que esta constituye una válida ayuda en la administración y en el comercio, hasta el punto de resultar indispensable cuando se supera cierto umbral de complejidad estatal, jurídica y económica; solo secundariamente, a partir de sus usos comerciales y administrativos, la escritura habría penetrado en la esfera de lo sagrado, desempeñando un papel determinante en la definición de las jerarquías sociales, y en las prácticas literarias, modificando profundamente las formas de la oralidad (Gilmont, 2004: 28). Se apostaría, así, en suma, por un nacimiento prevalentemente técnico-utilitario de la escritura, una apuesta que se halla en perfecta sintonía con la concepción de la emergencia del propio lenguaje articulado (el habla) en cuanto

\footnotetext{
${ }^{6}$ Hay que reconocer que la operación de definir con precisión lo que es la escritura entraña muchas dificultades y, por ende, que toda definición y toda periodización adolecen de cierta relatividad. Como recuerda Sini (2012), muchos antropólogos sostienen que los grafemas que aparecieron un poco por doquier durante el paleolítico y luego en el neolítico pueden ser considerados como una verdadera y propia forma de escritura, puesto que representaban el discurso (algún tipo de discurso) a través de una serie de convenciones gráficas, un vocabulario y una sintaxis específicos; sobre todo la escritura (o "script simbólico") aparecida en Europa alrededor del 5.500 a.C. (y por lo tanto anterior a la escritura cuneiforme) presenta rasgos y signos luego heredados por otras modalidades escriturales ya consideradas como históricas (como el minoico).
} 
instrumento útil para intercambiar rápida y eficazmente información factual acerca del mundo (la caza, el clima, las uniones, etc.). Sin embargo, así como resulta posible defender una emergencia prevalentemente simbólicoritual del lenguaje, también se puede considerar la escritura, ante todo, como un recurso mnésico - literalmente, para "llamar a la memoria", según la conocida respuesta del rey Thamus al dios Theuth en el Fedro platónico (274d-275b) - dirigido, más que al registro de datos relativos a productos y mercancías, a la re-presentación de historias identitarias y ejemplares; un recurso surgido en el transcurso de determinadas prácticas de ritualización de la experiencia común. Hay indicios de ello.

Ya en época histórica, en el siglo VIII a.C., se había desarrollado en Grecia una rica y compleja (y aun feliz, cabría añadir) cultura oral, pero por aquel entonces empezó a adoptarse, y adaptarse, el alfabeto fenicio. ¿Por qué? Bien es posible que el uso del alfabeto se difundiera siguiendo vías y rutas comerciales, pero hay pruebas de que desde el primer momento la escritura se puso al servicio de la tradición oral, como una especie de estratagema para potenciar y perpetuar el kleos, el "renombre" de héroes y difuntos (Svenbro, en Cavallo y Chartier, eds., 1995). Estaríamos, en tal caso, ante un uso escritural que se inscribiría, más que en procesos comunicativos de tipo utilitario, en ese tipo de comunicación que Iuri Lotman (1973 [1998]) define como comunicación Yo-Yo, con la que el sujeto no persigue transmitir información al otro, sino rememorar (y rememorarse) a sí mismo.

Naturalmente, fuera el que fuere el origen de la escritura simbólico-ritual, administrativo-jurídico, económico-comercial o, más probable aún, un origen multifactorial-, lo que aquí importa es que la posibilidad de "verter" y "fijar" en soportes materiales duraderos determinados tipos de información socialmente relevante creó nuevas modalidades de comunicación, expresividad y memoria, nuevas tanto desde un punto de vista cualitativo como cuantitativo. Podemos citar, en cuanto al primer punto de vista, la necesidad de activar - de forma variamente recreativa - el texto silente por parte del lector-intérprete (intérprete porque 
da voz al signo y, a la vez, porque comprende su significado); en cuanto al segundo, la acumulación "potencialmente ilimitada" del saber en archivos y bibliotecas.

En perspectiva semiótica, resultan relevantes los efectos de sentido que se derivaron de, y acompañaron, determinados cambios en las técnicas y en los artefactos de lectura. Como, por ejemplo, el progresivo abandono de los rollos en favor de los códices y la difusión de las formas de lectura silenciosa en detrimento de la lectura oralizada.

Desde los comienzos mismos de las prácticas de la escritura, los escribas, escribientes y escritores se han valido de diferentes soportes materiales: tablitas de arcilla, tablitas de madera enceradas, telas, derivados vegetales (como el papiro), pieles de animal (como el pergamino) y, finalmente, el papel y los más recientes soportes electrónicos digitales ${ }^{7}$. La difusión del papel (y de sus técnicas de fabricación ${ }^{8}$ ) es, por cierto, de suma importancia, puesto que sin un soporte tan abundante y relativamente barato como este nunca habría aumentado la producción de libros (Gilmont, 2004: 56).

Nuestras fuentes (sobre todo Cavallo, en Cavallo y Chartier, eds., 1995: 61-69) nos aclaran que el formato códice empezó a suplantar al formato rollo en el mundo de cultura latina a partir del siglo II d.C. y que

\footnotetext{
${ }^{7}$ Las superficies y los instrumentos al uso en la comunicación escrita no sólo contribuyen a dar forma a las técnicas y convenciones escriturales, sino también a las lectoras. Los cambios de soportes y herramientas, sin embargo, no afectan por igual a la escritura y a la lectura (una prueba más de esa asimetría de la que hablaremos más adelante). Las tecnologías digitales, por poner un ejemplo cercano en el tiempo, parecen haber modificado de forma relevante nuestra manera de escribir, pero no se puede decir lo mismo con respecto a la lectura, o al menos con respecto a la lectura de libros, ya que el formato electrónico (e-book) conserva la organización del libro impreso y no añade muchos más instrumentos de intervención sobre el texto. Por lo demás, acerca del impacto que las tecnologías digitales han tenido sobre los hábitos de lectura, se pueden consultar Cassany (2006: 171233) y Gubern (2010: 56-76).

${ }^{8}$ El papel, probablemente, se empezó a fabricar en China alrededor del siglo I d.C., pero su uso para la composición y copia de los manuscritos fue introducido en Europa por los musulmanes solo a comienzos del siglo XII y se generalizó entre los siglos XIII y XV (Gilmont, 2004: 52; Gubern, 2010: 27).
} 
este proceso condujo a una predominancia indiscutible del primero ya un siglo después. En el mundo griego, en cambio, el triunfo definitivo del códice se dio solo en el siglo V d.C. Tanto la difusión del códice como la resistencia plurisecular del rollo en el ámbito bizantino serían difíciles de explicar acudiendo solo a consideraciones de orden económico o material - la difusión del pergamino, el principal material para la fabricación de los códices hasta prácticamente la época de la imprenta, o la obvia constatación de que el códice, al ofrecer para la escritura ambos lados de cada hoja, es potencialmente más barato que el rollo—- Cabría destacar, más bien, cómo el códice se fue convirtiendo, a partir del siglo I d.C., en el instrumento de producción y divulgación escrita propio de la cultura cristiana. Por más barato, por supuesto, y por más cercano a las formas escritas ya propias del vulgo, como los prontuarios técnicos; pero también (¿sobre todo?) porque el rollo era un poderoso símbolo de la cultura pagana (clásica y helenística) de las clases dominantes, cultura rechazada por los cristianos. Y se pueden aducir, incluso, motivos más “imaginativos”, como hace Manguel (1996: 62) al recordarnos que los códices eran más fáciles de llevar escondidos bajo la ropa, algo extremamente útil si transportas y difundes escritos considerados como subversivos por la autoridad romana.

Sea como fuere, hay que señalar que la difusión del códice conllevó una serie de cambios en la manera de vivir y practicar la escritura y la lectura, y fue retroalimentada por ellos. En primer lugar, empezó un proceso de refuerzo de los dispositivos editoriales: la organización y la estandarización de la página (líneas, columnas, márgenes, etc.), las subdivisiones del texto, los recursos gráficos, etc. A partir del siglo $\mathrm{X}$, empezó a difundirse la scriptio discontinua y se puede decir que ya en el siglo XII tanto los espacios tipográficos para separar las palabras como los signos de puntuación eran recursos comunes (aunque con muchas variantes y oscilaciones).

En segundo lugar, el códice favoreció la emergencia de nuevas formas de lectura activa: el rollo se sostenía (y desenrollaba-enrollaba) con ambas manos, dejando a la vista porciones continuas del texto; el códice, 
en cambio, podía dejar una o incluso ambas manos libres para tomar anotaciones, apuntar glosas, escribir comentarios al margen, subrayar pasajes, saltar páginas rápidamente en búsqueda de información localizada. Así pues, la fragmentación del texto en esos "lugares singulares" que son las páginas y las nuevas modalidades activas de lectura, con la posibilidad de intervenir y escribir sobre el soporte textual, hicieron que el flujo de la lectura ininterrumpida dejara paso a una lectura más meditada, más concentrada y, posiblemente, cada vez más interiorizada.

No hay que olvidar que, durante siglos, la escritura se concibió como un recurso destinado a una re-oralización del texto, es decir, como una técnica dependiente de la oralidad, y no como una nueva forma de comunicación. No solo las lecturas públicas, por consiguiente, sino también las privadas eran en voz alta o, como mínimo, en voz baja, murmurada

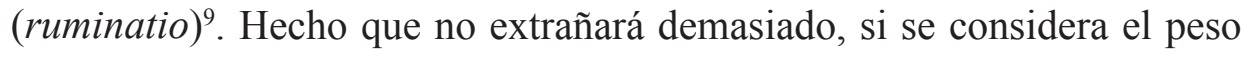
que aún hoy en día, en nuestro mundo enfermo de "hipergrafía", tiene la oralidad: todavía aprendemos a leer en voz alta y, aun mucho después de haber "interiorizado" la lectura, seguimos leyendo a los demás, seguimos escuchando historias leídas y seguimos "rumiando" nuestros textos (seguramente, suele "rumiarlos" quien esto escribe, así como "rumia" las palabras que escribe ${ }^{10}$ ).

Es interesante, en esta perspectiva, la relación causal que se suele establecer entre lectura oralizada y scriptio continua (sin espacios, sin puntuación). Sobre todo si se comparten las dudas expuestas por Cavallo y Chartier (1995: XII): ¿hasta qué punto la lectura oralizada y la silenciosa diferían y cuál era su relación con la scriptio continua? ¿No es posible que las dos formas de lectura hayan coexistido siempre, dependiendo tan sólo

\footnotetext{
${ }^{9}$ Habría qué averiguar, de todas formas, si y en qué medida en el mundo clásico (grecorromano) existía algo así como una "lectura privada". No se olvide que los géneros discursivos clásicos (teatro, epopeya, poesía, discurso oratorio) estaban destinados a la recitación y a la declamación.

${ }^{10}$ Otra vez el cuerpo y su estrecha relación con la lectura y la escritura: aun sin necesidad alguna, los labios, la lengua y la respiración, al igual que los ojos y las manos, acompañan el flujo de las palabras.
} 
de las circunstancias de la lectura?

En el mundo griego y luego en el de lengua latina, la scriptio continua era sin duda la norma y, de hecho, también era prevalente la lectura en voz alta, tanto pública como privada, hasta el punto de que se escribía teniendo en cuenta la recepción oral del texto. Viene al caso el celebérrimo pasaje de las Confesiones donde Agustín comenta, con estupor, el extraño proceder de su maestro Ambrosio: "Cuando él leía, sin embargo, mientras los ojos corrían por las páginas y la mente indagaba el significado, la voz y la lengua reposaban"11. A menudo, sigue Agustín en el mismo pasaje, los discípulos de Ambrosio lo veían "legentem tacite" y esa lectura silenciosa, supone Agustín, podía deberse a diferentes causas: para evitar que algún oyente curioso interrumpiera el flujo de la lectura con una pregunta, o quizá para "ahorrar" la voz que el obispo, ya mayor, perdía con facilidad.

Un momento decisivo en el pasaje desde una lectura en voz alta hasta una lectura silenciosa se dio, antes de que se difundiera la escritura discontinua, en los monasterios cristianos del siglo VI d.C., probablemente por motivos prácticos: respetar el silencio común y no molestar a los demás durante las horas de meditación individual y de reposo (Barthes y Compagnon, 1979: 186). Sin embargo, si San Benedicto en su regla presentaba la lectura silenciosa como una mera exigencia práctica (así como ocurrirá en las bibliotecas universitarias a partir del siglo XV), Isidoro de Sevilla ya defendía que la lectio tacita favorece la intelección del texto (Barthes y Compagnon, 1979: 187). El cambio de perspectiva es, desde un punto de vista semiótico, radical. Como nota Parkes:

Mientras en el siglo IV Agustín concebia aún las letras como símbolos de los sonidos, y los sonidos mismos como símbolos de las cosas pensadas, en el siglo VII Isidoro consideraba las letras como signos sin sonido y con el poder de comunicarnos silenciosamente (sine voce) la opinión de los ausentes [las

\footnotetext{
11 "Sed cum legebat, oculi ducebantur per paginas et cor intellectum rimabatur, vox autem et lingua quiescebant" (Agustín, Confesiones, VI, 3).
} 
auctoritates]. Las letras mismas son signos de las cosas. La escritura es un lenguaje visible que puede dirigir señales directas a la mente a través de los ojos (Parkes, 1995: 76; la traducción es mía).

También la percepción del texto como un medio para transmitir la autoridad religiosa o filosófica de un pasado lejano y el progresivo distanciamiento de la lengua escrita (el latín) de la lengua hablada (los diferentes vulgares) contribuyeron a alejar las prácticas de lectura de la oralización, por lo menos en contextos privados. Y así, en la primera mitad del siglo XII, Hugo de San Víctor, cuyos manuscritos ya estaban redactados en scriptio discontinua, recoge en su obra Didascalicon tres formas de lectura: la lectura en voz alta realizada para otros, la escucha de alguien que lee en voz alta y, finalmente, lo que él define como inspicere, el mirar con atención e inspeccionar la página para sí mismos (Saenger, en Cavallo y Chartier, eds., 1995); de modo semejante, nosotros hoy podemos visionar un texto.

En la Edad Media, pues, la costumbre de leer en solitario, mediante una lectura silenciosa, empieza a generalizarse. Sin embargo, a pesar de las mejoras en la composición de la página (mise en page) y de la difusión de la escritura discontinua, no solo la lectura seguirá siendo prevalentemente en voz alta (o murmurada) hasta los siglos XIII-XIV (Gilmont, 2004: 64), sino que la oralización del texto escrito continuará desempeñando un papel social muy relevante, teniendo también en cuenta los bajos niveles de alfabetización, hasta el siglo XVIII, como apuntan numerosos y prestigiosos testimonios ${ }^{12}$.

\footnotetext{
${ }^{12}$ Unos pocos ejemplos: en el capítulo I de la introducción a los Viajes de Marco Polo (siglo XIII), el narrador recuerda que en el libro se presentan "las cosas vistas como vistas, y como oídas las que así lo fueron", de modo que "cualquiera que haga su lectura o lo escuche deberá darle crédito por ser verdadero en todas su partes"; en el Prólogo a la Tragicomedia de Calisto y Melibea, que aparece en las ediciones de la obra a partir de 1502, el autor comenta los diferentes efectos que el texto puede tener "cuando diez personas se juntaren a oír esta comedia"; y el titulillo del capítulo LXVI de la segunda
} 
Ahora bien, así como parece legítima la operación de distinguir entre una oralidad primaria (comunicación oral en una sociedad que no conoce la escritura) y una oralidad secundaria (comunicación oral en una sociedad que sí conoce y emplea la escritura), deberíamos quizá distinguir entre una lectura oralizada primaria y una secundaria. La primaria sería una forma estrechamente dependiente de la oralidad: se escribe para poder luego oralizar lo escrito ${ }^{13}$; la lectura oralizada secundaria, en cambio, convive con la lectura silenciosa, y aún se subordina a ella. En la primera se movería aún Agustín, mientras que Isidoro de Sevilla y, sobre todo, Hugo de San Víctor, al diferenciar claramente la lectura en voz alta de la lectio tacita, privada, se hallarían ya en la segunda.

Por consiguiente, las formas de lectura oralizada típicas de las épocas moderna y contemporánea - lectura en voz alta (de periódicos, folletines, cuentos para dormir, etc.) para los que no saben o no pueden

parte del Don Quijote de la Mancha: “Que trata de lo que verá el que lo leyere, o lo oirá el que lo escuchare leer". También puede resultar interesante una breve historia diccionarial del lema "leer" (es suficiente consultar el Nuevo Tesoro Lexicográfico de la Lengua Española, accesible en línea a través de la página de la RAE). Descubrimos así que, si en el diccionario español-latín de Nebrija (1495) se recoge tanto "Leer aiuntando letras. Lego, is" como "Leer declarando. Expono, is", en el diccionario de Covarrubias (1611) "leer" se define únicamente como "pronunciar con palabras lo que por letras está escrito". La lectura silenciosa aparece, más de un siglo después, en el Diccionario de Autoridades (1734), aunque como mera alternativa a la lectura oralizada: "Pronunciar lo que está escrito, o repasarlo con los ojos", definición que sigue invariada hasta la edición de 1803 del diccionario académico, donde es sustituida por "Pasar la vista por lo escrito, o impreso, haciéndose cargo del valor de los caracteres, pronunciando o no pronunciando las palabras". Esta última definición se repite luego inalterada (con ligeras modificaciones a partir de 1884) hasta la edición de 2001 del DRAE, en la que finalmente desparece toda mención a la posibilidad de pronunciar las palabras: "Pasar la vista por lo escrito o impreso comprendiendo la significación de los caracteres empleados". Cabe decir que una definición semejante ya había figurado en el diccionario de Núñez de Taboada de 1825 ("Pasar la vista por lo escrito e impreso, haciéndose cargo del valor de los caracteres"), aunque también los diccionarios no académicos por lo común seguirán presentando la opción entre lectura oralizada y lectura silenciosa hasta nuestros días.

${ }^{13} \mathrm{Cfr}$. Quintiliano, Institutio oratoria, IX, 4, 138: "Denique, ut semel finiam, sic fere componendum quo modo pronuntiandum erit" ('Finalmente, para terminar de una vez, hay que componer así como se habrá de pronunciar'). 
leer, recitales de los autores para su público, lecturas radiofónicas, audiolibros, etc.- no serían pervivencias de la oralización primaria, cuando el signo escrito era un mero trazo gráfico para la recuperación del signo oral, el único que tendría sentido, sino que constituyen actuaciones (o actualizaciones) orales de textos cuyo sentido está inscrito (y puede ser hallado) en su propia forma gráfica.

Sea como fuere, la lectura silenciosa, ahí donde y cuando se produjo, marcó una profunda revolución en las prácticas interpretativas. Dejado a solas con el texto (aunque luego tendremos que matizar este "a solas") y alejado ya de la dimensión inmediata, directa y lineal de la oralidad, el lector acababa teniendo una relación más pausada, más meditada y más propositiva con el texto, lo que podía conducirle a formular interpretaciones más íntimas, más idiosincráticas, más independientes. No por casualidad a la lectura uniforme y cerrada del canon medieval (la Vulgata, Aristóteles y sus comentaristas, Horacio, Galeno, Boecio, etc.) se sustituyó pronto por la lectura crítica y abierta (y aun exploradora y creativa) de los humanistas.

También la imprenta, a partir del siglo XV, desempeñó un papel fundamental en este proceso de "apertura hermenéutica": abarató y aceleró la producción y la circulación de los textos y propició nuevas formas de escritura y nuevas formas editoriales (como las ediciones "de bolsillo" de Aldo Manuzio, las ediciones populares, los folletos, etc.), reforzando así, hasta límites antes insospechados, el problema del control de la lectura por parte de las autoridades culturales.

Sintomática, en este sentido, fue la reacción de la iglesia católica ante el proliferar de las traducciones de la Biblia y de los movimientos religiosos reformistas. De hecho, la curia romana respondió al desafío representado por la Reforma protestante reafirmando, durante el Concilio de Trento, el valor sagrado de la lectura canónica de la Vulgata latina: nadie, se afirma en un documento conciliar, en materia de fe y de moral, debía confiar en su propio juicio y tener la audacia: 
de sacar a las Sagradas Escrituras de su sentido propio, o de atribuirles interpretaciones contrarias a las que les da y les ha dado la Santa Madre Iglesia, a la que compete el juicio acerca del verdadero sentido y la verdadera interpretación de las Sagradas Escrituras, como tampoco interpretaciones opuestas al sentir unánime de los Padres (citado en Julia, en Cavallo y Chartier, eds., 1995: 278).

Así pues, como ya había ocurrido en el caso de las grandes herejías cristológicas (arrianismo, nestorianismo) y medievales (cátaros, valdenses), las jerarquías centrales de la iglesia reaccionaron a la crisis reafirmando su monopolio sobre la exégesis bíblica y el valor de dogma de su Interpretación. El hecho de que los feligreses no pudieran leer directamente la Vulgata era, en este sentido, una gran ayuda, de modo que cualquier versión vernácula de la Biblia fue condenada e inscrita en los índices de libros prohibidos. El único texto que era lícito traducir al vulgar era el catecismo tridentino.

La situación, por otra parte, no parecía mucho mejor del lado de los protestantes. Cierto es que Lutero y los reformistas, en un primer momento, habían abogado por una lectura directa e individual de los textos sagrados, rechazando, por ende, el papel mediador de la Iglesia y promoviendo las traducciones vulgares, pero pronto tuvieron que rectificar su postura a fin de evitar una proliferación excesiva y peligrosa de interpretaciones alternativas: acabaron así por defender que solo los lectores competentes, a saber, los teólogos, los obispos y los predicadores, eran los que podían comprender el significado de las escrituras y, por lo tanto, los únicos que debían dirigir y controlar su correcta interpretación (Gilmont, en Cavallo y Chartier, eds., 1995).

A partir del siglo XV, sin duda, la difusión de los libros y los progresos de la alfabetización volvieron cada vez más problemático el control eficaz de la circulación de los textos y de las interpretaciones. Pero ¿hasta qué punto? 
La llamada "revolución de la lectura" de los siglos XVIII y XIX está relacionada, si bien se mira, con el ascenso social de la burguesía, una clase con el interés, el tiempo y los recursos económicos suficientes para ocuparse de la gestión de la información, la implementación de la educación y el disfrute del tiempo libre: de aquí el éxito y la difusión de las publicaciones informativas (prensa), de la divulgación técnica, económica y científica y de la literatura de entretenimiento (novelas y poemas). Los valores liberales e individualistas de la ética burguesa marcaron la definitiva transformación del libro en una mercancía, del editor en un empresario, de los escritores en profesionales a sueldo y de los lectores en mercado. Ahora bien, la mercantilización de la información y del arte escritural no eliminó la preocupación por controlar y dirigir las interpretaciones socialmente aceptables (y políticamente útiles), hasta llegar a intervenciones extremas como la persecución y la eliminación de documentos y personas (las hogueras de libros en la Alemania nacionalsocialista, los procesos de reeducación popular en la China maoísta, el macartismo estadounidense, etc.).

En los regímenes (supuestamente) democráticos y liberales, sin embargo, el control suele asumir formas más sutiles, aunque no por ello menos eficaces. Según Petrucci (1995), por ejemplo, las campañas de alfabetización masiva del siglo XX apostaron por una potenciación de la capacidad de leer, pero no insistieron en igual medida en la capacidad de escribir, debido esto a que, si aún es posible controlar la producción y la circulación de los textos escritos, resulta muy difícil controlar lo que cada persona escribe: "La escritura es una capacidad individual y totalmente libre que se puede ejercer en cualquier circunstancia, en cualquier lugar y para producir lo que se quiera, más allá de todo control y aun de toda censura" (Petrucci, 1995: 415).

Si el control del discurso es, en suma, una cuestión capital para los aparatos de poder, lo es todavía más si la producción y la circulación de los textos se diversifica y acelera lo suficiente como para desbordar la capacidad 
de los medios de control disponibles ${ }^{14}$. Cabe recordar, al respecto, que existen, en opinión de Foucault (1970), tres modalidades fundamentales de exclusión discursiva, es decir, tres formas de deslegitimación y desaprobación de los discursos producidos o introducidos en el seno de una sociedad: la prohibición ("esto no se puede decir"), el rechazo ("esto no tiene sentido") y el juicio veridictorio ("esto es falso") ${ }^{15}$. Cada una de estas modalidades de exclusión

se apoya en una base institucional: está a la vez reforzada y acompañada por una densa serie de prácticas como la pedagogía, el sistema de libros, la edición, las bibliotecas, las sociedades de sabios de antaño, los laboratorios actuales. Pero es acompañada también, más profundamente sin duda, por la forma que tiene el saber de ponerse en práctica en una sociedad, en la que es valorado, distribuido, repartido y, en cierta forma, atribuido (Foucault, 1970: 22).

Al lado de las modalidades fundamentales, contaríamos además, según Foucault, con prácticas de exclusión "menores": el comentario y la glosa, el principio de autoría, la organización del saber en disciplinas, la defensa de pertinencias doctrinales y adecuaciones sociales, etc. Sin embargo, más que un elenco y una clasificación exhaustivos de tales

\footnotetext{
${ }^{14}$ Paradójicamente, las tecnologías digitales no solo contribuyen a acelerar y diversificar la producción y la circulación textuales, sino que también ofrecen nuevas y poderosas herramientas de control y exclusión: la posibilidad de bloquear ciertos tipos de fuentes y de información, por ejemplo, o algoritmos de búsqueda que permiten averiguar lo que leen y lo que escriben los usuarios. A esto se suma el conocido problema de la sobreinformación, puesto que sin adecuados instrumentos (intelectuales y técnicos) de discriminación y selección, demasiada información se convierte, sin más, en mala información o en falta de información.

${ }^{15}$ Foucault no habla, en realidad, de "juicio veridictorio", sino de "voluntad de verdad". Prefiero emplear aquí, sin embargo, la primera fórmula (a pesar de su imprecisión y fealdad), porque no sólo tratamos de la "voluntad", sino también de la "creación", la "defensa" y la "imposición" de determinadas verdades, y del "rechazo" y el "hostigamiento" de determinadas falsedades.
} 
prácticas, para nosotros lo importante del discurso foucaultiano es la insistencia en el hecho de que todo discurso (toda historia discursiva) - y Foucault, a lo largo de su carrera, estudió unas cuantas...- se genera y enmarca en un sistema de hábitos, tradiciones e instituciones (y tensiones, competencias y conflictos) culturales que determinan, globalmente, sus posibilidades de integración, recepción y deriva.

Volviendo al tema que aquí nos ocupa, resulta evidente para cualquier lector contemporáneo que la lectura de un texto concreto realizada por un lector individual es una operación que este lector realiza sobre (a partir de, en colaboración con) ese texto; a solas (quizás en la cama, antes de dormir, o en el tren, yendo al trabajo) o en compañía (quizá intercambiando opiniones con la amiga que se lo prestó o participando en algún grupo de discusión); activando, en todo caso, determinadas capacidades y competencias personales (atención, memoria, interés, saberes, etc.) y respetando determinadas características textuales (orden de las palabras, organización del discurso, divisiones internas, etc.). Pero no hay que olvidar que ni este lector ni este texto serían sin los otros textos, las otras lecturas y los otros lectores que los preceden y acompañan, sosteniendo y volviendo posible y consistente todo el proceso. Veamos más de cerca la cuestión.

\section{NADIE LEE SOLO (AUNQUE NO LO SEPA)}

Recuerda Roger Chartier (1995: 324-325) que según la metodología hermenéutica - y, más específicamente, según la metodología de Ricoeures necesario estudiar la lectura tanto en su dimensión privada (interacción dinámica entre lector y texto, respuesta a las solicitaciones textuales, trabajo interpretativo) como en su dimensión colectiva (relación dialógica entre las diferentes señales textuales y el horizonte de expectativas de un público); sin embargo, sigue Chartier, no debemos caer en el error de concebir el texto como un objeto abstracto, así como a menudo parece suceder en el ámbito hermenéutico o en el semiótico, ya que el texto que se lee es un 
objeto material y su concreta forma material se deriva de, y a la vez influye sobre, las prácticas y circunstancias lectoras; asimismo, la lectura no puede ser reducida a un puro proceso intelectual de comprensión e interpretación, puesto que también las concretas modalidades y circunstancias en la que un texto es leído intervienen en su recepción individual y social.

Lo que aquí nos interesa es, una vez más, la relación dialéctica que se da entre estas dos dimensiones de la lectura, la privada y la colectiva, alrededor de ese objeto de "confluencia semiótica" que es el texto escrito.

Que la lectura sea una práctica condicionada por diferentes determinantes de tipo social y cultural no es desde luego una afirmación novedosa. Al respecto, señala Cassany (2006: 33-34) que aquellos autores que hacen hincapié en esta dimensión sociocultural de la comunicación escrita ponen énfasis, por lo común, en los siguientes tres puntos: 1) tanto el significado de las palabras y expresiones que integran el texto como los conocimientos que aporta el lector tienen un origen social; 2) todo discurso surge y se define a partir de una visión del mundo y ésta también tiene un origen social; 3) los discursos, los autores y los lectores no operan de forma aislada, sino que participan en instituciones y en prácticas colectivas. No se trata de evidencias que, al parecer, puedan obviarse con facilidad.

Como tampoco puede obviarse el hecho de que para cada lector, con sus propias costumbres, sus intereses, sus idiosincrasias, sus caprichos, sus manías, sus azares, cada lectura es una experiencia individual y única, un trabajo interpretativo que él o ella lleva a cabo, en cuerpo y espíritu, a expensas de su tiempo y de su energía.

Considérense las seis definiciones de Barthes y Compagnon que hemos encontrado en nuestro primer apartado: i) "leer es una técnica", ii) "leer es una práctica social", iii) "leer es una forma de gestualidad (y corporeidad)", iv) "leer es una forma de sabiduría", v) "leer es un método", y vi) "leer es una actividad voluptuosa". En primera instancia y con cierta aproximación, se podría decir que $i$ y ii dependen sobre todo de la dimensión colectiva (sociocultural) de la lectura, que iii y vi dependen sobre todo de su dimensión privada (cognitivo-fenomenológica) y que $i v$ 
y $v$ dependen de ambas dimensiones. Para luego, en segunda o tercera instancia, reconocer que cualquier definición (y cualquier aspecto) de la lectura se refiere, necesariamente, a sucesos y procesos privados (relativos al intérprete) así como a sucesos y procesos públicos (relativos a los hábitos, las circunstancias y las contingencias de la interpretación).

\subsection{La enseñanza y el aprendizaje del leer y de la lectura}

Los niños aprenden a hablar con cierta fluidez en los primeros cuatro años de vida: aprenden a coordinar sus acciones y sus actos de habla con los de las personas con quienes interactúan; reconocen y aprenden a emplear patrones (estadísticamente) significativos en las formas y estructuras lingüísticas que se les insta a manejar; empiezan a moverse en el lenguaje de forma funcional, plástica y creativa. El aprendizaje de la lectura y la escritura (es decir: la alfabetización) se inserta en este proceso y lo "desdobla", por así decirlo, pasando de una materia expresiva fónica y corporal a una gráfica y añadiendo al dominio comunicativo nuevas formas de organización e interacción discursiva.

Como hemos visto, la historia de la comunicación escrita es también la historia de una progresiva y extendida alfabetización, desde el control de la escritura por parte de élites técnicas (escribas) o castas sociales (sacerdotes), pasando por la difusión de la escritura en estratos sociales cada vez más consistentes y diversificados, hasta llegar a los procesos de alfabetización masiva del siglo XX.

Esta progresiva extensión y diversificación de la comunicación escrita nos plantea con fuerza la cuestión del papel ejercido por los métodos de enseñanza y las políticas educativas, ya que todo sistema de educación, como sostuvo Foucault (1970: 45), "es una forma política de mantener o de modificar la adecuación [social] de los discursos, con los saberes y poderes que implican”. ¿Qué nos enseñan cuando nos enseñan a leer? Y, sobre todo, ¿qué nos enseñan a leer? Como recuerda Manguel (1996: 81), los métodos de enseñanza "no solo encarnan las convenciones de nuestra 
sociedad particular en lo que respecta a la lectura y a la escritura - la canalización de información, las jerarquías de conocimiento y de poder-, sino que también determinan y limitan las maneras en que utilizamos esa capacidad de leer". La comunicación escrita es, de por sí, como toda forma de comunicación, un hecho colectivo, transpersonal, y como toda forma de comunicación participa en (determina y es determinada por) las dinámicas sociales. El lector individual puede cuestionar tales dinámicas, puede reaccionar a ellas e incluso rebelarse, pero lo que no puede hacer es dejar de posicionarse con respecto a ellas.

Hay que notar, en primer término, que las actividades de lectura y las de escritura son, sin duda, co-implicativas, pero asimétricas.

En las épocas de la lectura oralizada y de la scriptio continua, por ejemplo, había probablemente menos personas capaces de leer que de escribir: la lectura en voz alta de un texto continuo era una actividad muy lenta y complicada y no todos los escribas aprendían a realizarla (Gilmont, 2004: 64). Ahora, en cambio, o por lo menos desde el siglo XIV hasta el siglo $\mathrm{XX}$, hay más leyentes que escribientes (por no hablar de escritores). Esto se explica, en parte, por las políticas educativas, que, como comentábamos al finalizar el apartado anterior, se centran sobre todo en la enseñanza de la lectura, y en parte por el hecho de que el leer se ha convertido, en virtud de la mejora de los dispositivos editoriales, la estandarización de los recursos gráficos y la mercantilización de la información y la literatura, en una actividad mucho menos exigente que el escribir. A decir verdad, en las últimas décadas las nuevas tecnologías, sobre todo los servicios de mensajería, los chats y los comentarios en la prensa y los fórums digitales, han reforzado las prácticas escritoras, promoviendo, dadas la rapidez y las limitaciones impuestas por los formatos tecnológicos, "extrañas" escrituras sincopadas, comprimidas y pictográficas.

Hay que recordar, en segundo lugar, que existen diferentes niveles de lectura, más o menos compenetrados entre sí según el hábito de cada lector y de cada comunidad. Podemos destacar, en primer término, dos dimensiones fundamentales en toda práctica lectora, una lineal y una 
compleja. La primera se refiere al flujo lineal de la lectura (grafemas, lexemas, oraciones, párrafos), la segunda a la interpretación consistente que hay que dar al texto. No por nada se suele diferenciar, hoy en día, la alfabetización, como capacidad de oralizar lo escrito, de la alfabetización funcional, como capacidad de comprender el significado de lo que se lee (Cassany, 2006: 21).

En cierto sentido, esta distinción viene de lejos. En el mundo griego, por ejemplo, para hablar de la lectura se empleaba, por un lado, el verbo anagignoskein, 'reconocer' las letras y sus agrupamientos en sílabas, palabras, frases (con determinaciones adverbiales de tipo calificativo: tacheos, 'rápidamente', bradeos, 'apenas', ortos, 'rectamente', etc.), y, por otro, algunos verbos basados en metáforas espaciales, como dierchomai y diecsemimi: 'recorrer', 'atravesar' el texto en profundidad (Cavallo y Chartier, 1995: XIV); y en el mundo de cultura latina se solía diferenciar entre el entendimiento de la letra escrita (littera), la comprensión del significado (sensus) y la comprensión de la doctrina expresada en el texto (sententia) (Cavallo y Chartier, 1995: XXIV) ${ }^{16}$.

Parece evidente, finalmente, que aprender a leer (aun funcionalmente) y adquirir el hábito de la lectura son procesos bien distintos. Una persona que haya aprendido a leer puede llegar a reconocer y entender automáticamente cualquier escritura en el idioma al uso: rótulos, etiquetas, eslóganes, titulares, etc. Asimismo, puede recuperar todo tipo de información contenida en noticias, posologías, normativas, instrucciones, etc. Y aun así estar muy lejos de adquirir el hábito de la lectura como práctica e interacción consistente con diferentes tipos de textos escritos. A esto nos referimos cuando decimos de alguien que "no le gusta leer": la lectura consistente de un texto, y sobre todo de esos textos por antonomasia

\footnotetext{
${ }^{16}$ Podemos, en efecto, leer textos escritos en un idioma que desconocemos, si estamos al tanto del código alfabético correspondiente. Léanse los siguientes enunciados: i) "Superc alifragilisticoespialidoso". ii) "Pape satán, pape satán aleppe". iii) "Anaal nathrakh, urth vas bethud, dokhjel djenvé". Sin duda se pueden leer (o mejor dicho: su littera se puede leer, si bien con alguna dificultad o duda). Pero ¿qué significan? Nada, que yo sepa. Son ejemplos textuales de lenguas inventadas.
} 
que son los libros, implica cierto coste temporal y energético, coste que sólo un interés específico puede asumir y que sólo un hábito bien radicado puede soportar en el tiempo. Por este motivo los lectores suelen ser menos que los leyentes.

Considérese que el saber leer, y más aún el hábito de la lectura, implican el aprendizaje y el dominio de una serie de competencias específicas, interrelacionadas pero parcialmente independientes (es decir, cierto nivel de adquisición de una de tales competencias no implica necesariamente un igual nivel de adquisición de las demás):

- Competencia socio-pragmática: relativa al uso y la estructura de los textos (porque, para poder leer un texto, es necesario reconocerlo en tanto que texto, saber dónde encontrarlo y cómo tener acceso a él, saber cómo funciona, saber lo que con él se puede o no se puede hacer, etc.).

- Competencia lingüística:

- competencia alfabética (o grafémico-fonémica): relativa al sistema de correspondencias entre los fonemas de una lengua y los grafemas que los representan (el alfabeto) ${ }^{17}$;

- competencia léxico-semántica: relativa al reconocimiento y a la interpretación de las unidades significativas (palabras, perífrasis, locuciones, modismos, paremias, etc.);

- competencia morfo-sintáctica: relativa a las modificaciones

\footnotetext{
${ }^{17}$ Estas correspondencias, como bien sabemos, por lo común distan de ser biunívocas, aun cuando el alfabeto se ha estandarizado y se han eliminado (casi) todas las variedades y oscilaciones: hay grafemas a los que no corresponde ningún fonema, hay fonemas a los que no corresponde ningún grafema, hay grafemas que, según el contexto en que se hallan, indican fonemas diferentes y grafemas diferentes que indican el mismo fonema, hay grafemas meramente reguladores, etc. Cabe destacar, asimismo, que es posible, por lo menos idealiter, aprender a leer sin saber oralizar bien (o en absoluto) lo que se lee, dándole a la palabra escrita un estatus autónomo con respecto a la palabra oral u oralizándola (así como se suele hacer, en efecto, con el latín clásico) según códigos alfabéticos diferentes a los de los hablantes-leyentes originarios del texto.
} 
(p. ej.: flexión y composición) y relaciones (p. ej.: concordancias y regencias) que integran y cohesionan unidades discursivas más amplias (sintagmas, oraciones, párrafos, etc.);

- competencia estilística: relativa a las variedades de lengua que se emplean en las diferentes situaciones socio-comunicativas (variedades diafásicas).

- Competencia discursiva y retórica: relativa a la organización específica del material lingüístico (y a los esquemas compositivos y recursos expresivos típicos) según las funciones propias de cada texto (por ejemplo: delectāre, movēre o docēre).

- Competencia cultural (o enciclopédica): relativa a los conocimientos intertextuales y extratextuales que se activan (o que habría que activar) para dar una interpretación consistente al texto.

Dependiendo del sistema educativo (y de las políticas que lo informan), de las circunstancias e intereses de los discentes y de los textos a los que tienen acceso, el aprendizaje y la activación diferencial de todas estas competencias puede crear — y de hecho crea — una amplia y variada tipología de leyentes y lectores ${ }^{18}$. Estos, además, pueden llegar a enfrentarse —y en determinados ámbitos culturales hasta es común que

\footnotetext{
${ }^{18}$ Las competencias lectoras, obviamente, tienen su contrapartida en otras tantas ignorancias: no podemos leer textos que no sabemos usar (para un lector no acostumbrado, por ejemplo, leer un cómic japonés, empezando por la "última página" y siguiendo las viñetas de derecha a izquierda, es todo un reto; ¿y se puede imaginar Ud. leyendo un rollo en scripta continua?); no podemos leer un texto escrito en un idioma que desconocemos por completo (aunque es notable todo lo que podemos entender con unas competencias alfabética y léxico-semántica aun muy defectuosas); no podemos leer textos que sobrepasan nuestra competencia discursiva (de ahí los juicios negativos de ciertos lectores domingueros que han intentado leer, quién sabe por qué, obras como el Ulises, de Joyce, o El ruido y la furia, de Faulkner) ni podemos leer textos que requieren competencias culturales que no aprendimos (la comprensión de un texto especializado de química o de matemática, por ejemplo, está fuera de mi alcance).
} 
se enfrenten - a textos escritos y a situaciones de lectura muy diferentes entre sí; por ello, a partir de los propios hábitos y competencias adquiridos por cada lector y de los estándares textuales de la sociedad, resulta posible clasificar los textos en triviales (de lectura fácil, si no automática), no triviales (de lectura empeñada) y aun exigentes (de lectura trabajosa) ${ }^{19}$. Sólo los lectores empedernidos o los muy curiosos pueden apreciar el reto que les supone la lectura de un texto exigente, mientras que la mayoría de leyentes se contenta con la capacidad de reconocer y emplear una gran cantidad de textos triviales. Habremos de volver sobre este punto.

\subsection{Los procesos de lectura orientada}

Como vino a decir Foucault (1970: 14), en toda sociedad "la producción del discurso está a la vez controlada, seleccionada y redistribuida por cierto número de procedimientos que tienen por función conjurar sus poderes y peligros, dominar el acontecimiento aleatorio y esquivar su pesada y temible materialidad". La educación es, como acabamos de ver, uno de tales procedimientos, ya que a través de ella se trata de controlar la adecuación de las producciones e interpretaciones de los discentes a cierto orden discursivo y social.

Uno de los aspectos de este proceso, sin duda no el más relevante, pero sí pertinente para nosotros, consiste en aquellos recursos y procedimientos cuyo fin es el de orientar la lectura de un texto dado hacia cierta interpretación (o por lo menos hacia cierto régimen de interpretación).

Hay muchos "instrumentos" socio-culturales que orientan y uniforman las actividades lectoras. Empezando por el control y la

\footnotetext{
${ }^{19}$ Tendríamos, luego, aquellos textos cuya lectura no solo requiere concentración, trabajo y excelentes competencias pragmáticas, lingüísticas, discursivas y enciclopédicas, sino también la puesta en marcha de hipótesis interpretativas que conducen a la formulación de nuevos saberes o a la modificación de las competencias previas. Las grandes obras de arte serían textos de este tipo, como recuerda a menudo Iuri Lotman, algo hiperbólicamente: textos dados, al principio, en ningún lenguaje.
} 
estandarización de las situaciones de lectura. ¿Cuándo y dónde se puede y aun se debe leer? No es una cuestión baladí, por lo menos en la medida en que la organización de un espacio y un tiempo oficiales para la lectura influye en la circulación y en el uso de los textos y reduce el riesgo de que los lectores "rompan" el ritmo y los límites de los hábitos establecidos. En este sentido, aunque la extensión de la alfabetización ha conllevado también un ensanchamiento de los ámbitos y los momentos dedicados a la lectura, aún hoy en día muchos lectores siguen leyendo (y adquieren lo que van a leer) en lugares y tiempos predeterminados.

Por lo demás, podemos dividir los factores que intervienen en la orientación de la lectura en factores intratextuales e intertextuales. Entre los primeros, habríamos de incluir todos aquellos elementos funcionales que acompañan un texto escrito y dan pistas previas, a menudo estereotípicas, acerca de lo que el lector (supuestamente) podrá encontrar en él: los títulos, para empezar; pero también el nombre del autor y la composición de la portada, en el caso de un libro. Los prefacios y las introducciones a un texto desempeñarían el mismo papel, aunque de forma más elaborada. Los factores intertextuales remitirían, en cambio, a aquellos otros metatextos - estudios, artículos, comentarios, reseñas, resúmenes, etc.— producidos por las instituciones culturales — como academias, revistas, círculos, editoriales, etc. - a fin de promover, explicar y explicitar los valores y las bondades de un texto dado, de un conjunto de textos o de un determinado canon frente a la comunidad de lectores (especialistas o no).

Existen, finalmente, y esto es lo más importante, intervenciones y estrategias políticas, ideológicas y económicas de gran alcance dirigidas a la orientación de la lectura. Las más directas e invasivas son, qué duda cabe, la prohibición y la censura. "El poder absoluto", escribe Manguel (1996: 291), pero podemos extender su afirmación a toda clase de poder, "necesita que todas las lecturas sean la lectura oficial; en lugar de bibliotecas completas, de diversas opiniones, la palabra del gobernante debe bastar. [...] Por eso la censura, de una u otra forma, es el corolario de todo poder, y la historia de la lectura está iluminada con una hilera, 
al parecer interminable, de hogueras encendidas por los censores". Y no sólo hogueras, sino también secuestros de ediciones, restricciones de imprenta y de venta e índices de libros prohibidos, hasta llegar, a veces, a la aniquilación física de escritores y lectores.

El uso de la coerción y de la fuerza no es, no obstante, el único sistema, y puede que ni siquiera el más efectivo, para controlar la producción, la circulación y el consumo textuales; a tal fin, el establecimiento y la divulgación —a la vez institucional, escolar y comercial— de un canon oficial de lecturas suele dar muy buenos resultados ${ }^{20}$. Si el problema es, en suma, "conjurar los poderes y peligros" del discurso y tratar de dominar "el acontecimiento aleatorio", empleando una vez más las palabras de Foucault con las que empezamos este apartado, o, en otros términos, organizar, enseñar y defender (¿hasta qué punto?) cierto orden cultural, más o menos dinámico, jerárquico y heterogéneo, el establecimiento y mantenimiento de un canon textual fuerte - que especifica lo que es obligatorio, importante o aconsejable leer- da ciertas garantías, por lo menos a corto-medio plazo, de que tendrá escasa circulación todo texto que no encaje en, o no ejemplifique bien, los modelos al uso ( $\sin$ descartar, por supuesto, el "riesgo" de que un texto anómalo sea canonizado en el ámbito de específicas oposiciones culturales o que incluso se convierta, con el paso del tiempo, en el texto fundador de un nuevo canon).

Un discurso aparte merecen las estrategias comerciales de las editoriales, instituciones que, como se sabe, en el mejor de los casos deben compaginar sus políticas y apuestas culturales con la exigencia de beneficios económicos y que, en el peor de los casos, lo único que persiguen son estos beneficios. La consecuente tendencia a evitar riesgos y a seguir el mercado

\footnotetext{
20 "Se define como canon un conjunto (o repertorio) limitado de textos (o de rasgos textuales codificados) pertinentes y relevantes desde la perspectiva de un género (de un dominio conversacional) determinado. En un canon textual se recogen los textos más conocidos, duraderos y representativos para una comunidad de intérpretes, aquellos textos que más conexiones establecen con el intertexto cultural. El canon se nos presenta, por tanto, como una forma más de autoorganización semiósica: un sistema (aproximado) de clasificación y jerarquización de los textos socialmente pertinentes" (Lampis, 2013: 57-58).
} 
y sus modas, alimentando el uno y las otras, favoreciendo la producción, traducción y circulación de obras canónicas ${ }^{21}$ y compartimentando los lectores en áreas de consumo (por géneros, disciplinas e intereses), no ayuda ciertamente a la emergencia de voces y oídos capaces de funcionar con cierta independencia del coro.

Todo esto, si bien se mira, tiene que ver, por un lado, con el acceso material a los textos y, por otro, con su acceso interpretativo, ya que podemos leer solo aquellos textos que están a nuestro alcance y podemos interpretarlos solo a partir de lo que nos enseñaron y aprendimos: somos los lectores que nuestra historia, los demás y las circunstancias nos permiten $\operatorname{ser}^{22}$.

En nuestros tiempos, las librerías especializadas, las grandes bibliotecas y redes bibliotecarias y la circulación (legal o "pirata") de textos en formato electrónico nos permiten acceder - no siempre fácil o gratuitamente, la verdad sea dicha - a fondos bibliográficos enormes, inabarcables; no obstante, un lector que no tuviera autoridades, enseñantes, colaboradores o compañeros que le ayudasen a orientarse en la red de recursos y a orientar, sobre todo, sus elecciones y prioridades, estaría perdido. Así que, si antaño el problema era recuperar y acceder a los textos, hoy en día el gran problema es cribarlos de forma inteligente.

Hablamos, algunos párrafos más arriba, de la función de control cultural (y aun político e ideológico) que desempeña el canon textual; debemos ahora reconocer su "utilidad", por así decirlo, ya que el canon,

\footnotetext{
21 "Un texto canonizado es un texto que entra a formar parte de un canon. Un texto canónico es, en cambio, un texto cuya organización significante se construye e identifica con arreglo a las especificaciones (a los hábitos) previstos por el canon (la noción de canon sería, en este sentido, equiparable a la de maniera). Los textos canónicos ("manieristas"), por consiguiente, comportan muy pocos cambios (o ninguno) en los procesos de creación e interpretación textual. Son, por lo común, y aunque pueda sonar algo paradójico, textos triviales que no encuentran cabida, sino efímera, en canon alguno" (Lampis, 2013: 58). ${ }^{22}$ Naturalmente, esto no equivale a defender de forma contraintuitiva, y en contraste con la observación histórica, el inmovilismo de las prácticas interpretativas y semióticas: los efectos de las idiosincrasias, las singularidades y las contingencias que actúan en y sobre el sistema se acumulan, se entretejen complejamente, y el sistema deriva.
} 
por lo menos en tanto que estructura abierta y dinámica que participa en la autorregulación cultural, ofrece al lector un primer principio de orientación - lo que podría ser y aun debería ser un primer principio de orientación - en estos ámbitos y tiempos de proliferación excesiva de textos y lecturas. Aunque, claro, la operación (¿contrarreformista?) de calificar de "excesiva" cierta producción y circulación textual es y seguirá siendo materia de discusión y de debate.

\subsection{La comprensión de lo leído}

Sabemos que un mismo texto se suele interpretar de formas diferentes al variar las competencias (e ignorancias) de los lectores y los momentos y las circunstancias de recepción. ¿Es legítimo concluir, por ende, que existen infinitas lecturas posibles del texto? La mayoría de los investigadores sugieren cautela. Greimas y Courtés, por ejemplo, aun admitiendo sin vacilar que un texto puede originar diferentes interpretaciones (diferentes "isotopías de lectura"), insisten en la gratuidad de la hipótesis de que existe un número ilimitado de ellas, principalmente porque se trata de una hipótesis inverificable:

La impresión de «apertura» infinita del texto la producen a menudo lecturas parciales: tal o cual secuencia del discurso, tomada separadamente, puede conllevar, en efecto, un gran número de isotopías; sin embargo, estas quedan en suspenso a causa de su incompatibilidad con las secuencias siguientes que tienen por función - entre otras - el desambiguar la secuencia poli-isótopa, no dejando subsistir en el texto global sino un número restringido de lecturas posibles. A las coerciones inscritas en el texto mismo, se agregan las del medio sociocultural circundante: la competencia textual del lector se encuentra inscrita y condicionada por la episteme que abarca un estado semiocultural dado (Greimas y Courtés, 1990: 236). 
Así pues, no hay un número ilimitado de lecturas (ni siquiera si se considera el "gran tiempo" de las obras de arte). No obstante, dada la organización polifónica (o plurilingüística) de los textos no triviales, dada la no coincidencia de las enciclopedias del lector y del autor, dadas las derivas epistémicas y culturales y dadas las contingencias que intervienen en la circulación y la interpretación de los textos, quizá sí haya un número (muy) indefinido de ellas ${ }^{23}$. Habría que preguntarse, además, qué clase de lectura - profunda, detallada, documentada, analítica - habría que llevar a cabo para trazar los significados "exactos" del texto; lo que, en cierto sentido, equivale a preguntarnos: ¿por qué leemos? Solo un número muy exiguo de lectores acometen la ardua tarea de hacer coherentes, de forma metódica y comprobable, todos los aspectos de su interpretación del texto; y lo hacen, por lo común, a fin de poder producir una explicación crítica - si no científica - de lo que el texto trata de decir y de cómo lo dice.

¿En qué medida el texto es el producto de la actividad lectora? En opinión de Eco (1979), el texto es un sistema de artificios expresivos

\footnotetext{
${ }^{23}$ Eco (1979: 7) recuerda que Lévi-Strauss criticó su temprana Opera aperta porque, en opinión del célebre antropólogo, una obra escrita es siempre un objeto cerrado: un objeto dotado de propiedades específicas y analizables y que, por tanto, puede ser enteramente definido a partir de tales propiedades. Sin embargo, observa Eco, el lector está llamado a llevar a cabo "una serie de elecciones interpretativas que, si no son infinitas, sí son por lo menos indefinidas, y en cualquier caso múltiples. ¿Por qué entonces no hablar de 'apertura'? Postular la cooperación del lector no quiere decir contaminar el análisis estructural con elementos extra-textuales. El lector como principio activo de la interpretación es parte del cuadro generativo del propio texto". Desde el punto de vista del lector, recuerda Manguel (1996: 100) que sus amigos y él tomaron la posibilidad de interpretar un mismo texto de formas diferentes como una prueba más de su libertad como lectores: "Si en la lectura no existía nada parecido a una 'última palabra', ninguna autoridad podía imponernos una lectura 'correcta'. Con el tiempo nos dimos cuenta de que algunas lecturas eran mejores que otras: más informadas, más lúcidas, más estimulantes, más agradables, más perturbadoras. Pero aquella flamante sensación de libertad nunca nos abandonó, e incluso ahora, al disfrutar de un libro que cierto crítico ha condenado o al desechar otro que ha recibido cálidos elogios, me parece recordar con gran nitidez aquel sentimiento de rebeldía".
} 
que el destinatario debe actualizar, de modo que todo texto también prevé, genética y estratégicamente, las competencias lectoras necesarias para su actualización; el texto, en otros términos, a través de sus estrategias expresivas y narrativas, construye o por lo menos selecciona sus lectores.

El punto importante, aquí, es que si tiene razón Eco y el tema (y tono) general de un texto escrito - topic en inglés, sujet en francés y ruso- es algo que el lector, si no lo aprende de los demás, infiere (abductivamente) a partir de los primeros compases del texto (incluyendo el título, la portada, el nombre del autor, etc.), algo que finalmente orienta y dirige la selección y actualización de determinadas isotopías o recorridos de lectura, entonces es primordial comprender en qué se basa el lector para formular y seguir una inferencia dada y no otra. Naturalmente, el texto mismo (el intratexto) puede, a lo largo de la lectura, "sugerir" o "pretender" que se reconsidere, reformule y aun sustituya la hipótesis interpretativa inicial, pero las nuevas inferencias, así como la inferencia inicial, dependerán en todo caso de la competencia textual y cultural previa del lector, es decir, de sus saberes y hábitos intertextuales y extratextuales (saberes y hábitos que definen, no se olvide, tanto una memoria textual como un sistema de expectativas) ${ }^{24}$. El proceso interpretativo se resuelve así en un paseo inferencial, como lo llama Eco (1979: 118), por los repertorios de lo ya dicho. Durante este proceso, en el transcurso del paseo, al compás de las expectativas e inferencias activadas, confirmadas y descartadas, los significados del texto y los saberes del lector se amoldan, transforman y frustran mutuamente.

Podemos, por ende, concluir que un texto dado es trivial cuando no exige de las competencias previas del lector, dadas por supuestas, ninguna transformación: un texto trivial es absolutamente canónico y le pide al lector sólo lo que él ya conoce. La trivialidad o no trivialidad de un texto no dependería, pues, sólo de lo que el texto necesita y pide, sino también de lo

\footnotetext{
${ }^{24}$ Otro pequeño apunte personal: como lector, diría que al menos dos veces en mi vida me he enfrentado a textos narrativos que han desbaratado y desbordado por completo mis expectativas previas y mis primeras inferencias: El castillo, de Franz Kafka, y El almuerzo desnudo, de William Burroughs.
} 
que el lector conoce y puede dar. Para los niños muy pequeños, lectores y exégetas en ciernes, no hay textos triviales, mientras que para los lectores muy curtidos la trivialidad impera (casi) por doquier.

No será ocioso recordar, además, que lo que todo lector hace, es, en último término, producir - o intentar producir - una interpretación consistente del texto leído y que la consistencia de una interpretación depende de automatismos, hábitos y apuestas interpretativos que sólo pueden ser corroborados o enjuiciados a partir de determinados saberes de orden intratextual, intertextual y extratextual. Pero tales saberes no serían suficientes si no consideráramos que la comprensión del texto depende, asimismo, de las concretas circunstancias, regímenes y modalidades de lectura y de cómo se interpreta la propia práctica lectora: es la relación del lector con la lectura lo que ante todo orienta y determina la interpretación del texto.

En opinión de Eco (1979), por ejemplo, todo lector empírico tiene la obligación de aproximarse al Lector Modelo previsto por el texto, lo que implica el deber filológico de recuperar con la máxima fidelidad posible los códigos del emisor; por consiguiente, interpretar un texto escrito significa sobre todo actualizar semánticamente "lo que el texto, en tanto que estrategia, quiere decir a través de la cooperación con su Lector Modelo" (Eco, 1979: 179). Sin embargo, este "escrúpulo filológico" (Lampis, 2013) no puede ser considerado como un deber absoluto, al igual que no puede ser considerada como absoluta la disyuntiva establecida por el autor italiano entre una interpretación aceptable del texto, por un lado, y su mero uso o abuso, por otro. No por nada resulta posible referir a la distinción entre abuso textual y cooperación interpretativa lo que sostiene el propio Eco acerca de la distinción entre cooperación interpretativa e interpretación crítica: "las fronteras entre estas dos actividades son muy lábiles, y hay que establecerlas en términos de intensidad cooperativa y de claridad y lucidez en el exponer los resultados de la cooperación realizada" (Eco, 1979: 183). Se dan, de hecho, abusos textuales perpetrados por críticos y 
hasta por comunidades científicas ${ }^{25}$.

¿Contamos, pues, con diferentes tipos de lectura? Desde luego. Si tomáramos en cuenta, por ejemplo, la modalidad y la cantidad de trabajo interpretativo que el lector realiza con el texto, podríamos indicar, al lado de la ya clásica dicotomía "lectura intensiva-lectura extensiva" y a la ya referida "lectura analítica-lectura ingenua", los siguientes tipos: lectura automática, lectura superficial, lectura profunda (o estudio), lectura obsesiva, lectura empática, lectura salvaje (una lectura no sólo ingenua, sino también asistemática, casual, irreflexiva), lectura anárquica (en contra de toda autoridad crítica o lectura canónica, defendida por autores como Susan Sontag y Hans Magnus Enzensberger), lectura crítica, lectura científica, etc.

Si consideráramos, en cambio, los fines u objetivos que se persiguen con la lectura, tendríamos: lectura de entretenimiento (o de evasión, y hasta "narcótica"), lectura de formación, lectura práctica (para aprender a "hacer cosas"), lectura informativa, lectura explicativa, lectura ideológica, lectura estética, lectura ritual, etc. O según la causa: lectura obligatoria, lectura aconsejada, lectura regalo, lectura curiosa, lectura casual, etc. O según los momentos y la frecuencia: lectura rutinaria, lectura ocasional, lectura a largo plazo, lectura para ratos libres, etc. O según el lugar: lectura escolar, lectura doméstica, lectura de playa, lectura para viajes, etc.

Ya lo dijimos: hay muchos lectores (y aun más leyentes) y muchas lecturas posibles (que se alternan, se superponen, se entretejen, se excluyen, coexisten, etc.). Sin embargo, lo que aquí de verdad importa es que todas estas formas y ritmos de lectura constituyen otras tantas maneras de interpretar el trabajo textual y de acceder al significado del texto. El lector

\footnotetext{
${ }^{25}$ En todo caso, "el significado de un texto se amplía de acuerdo con la capacidad y los deseos del lector [...]. Esa trasmigración del significado puede enriquecer o empobrecer el texto mismo; inevitablemente, lo contamina de las circunstancias del lector" (Manguel, 1996: 222-223). El crítico o estudioso textual no sería, en este sentido, sino un tipo especial de lector, "un lector cooperante que, tras actualizar el texto, cuenta [¿narrativiza?] sus propios pasos cooperativos, y vuelve evidente el modo en el que el autor, a través de su estrategia textual, lo ha llevado a cooperar de esa forma" (Eco, 1979: 183).
} 
no es una entidad abstracta, nadie lo olvide, ni lo es el texto, ni lo es la interacción que se lleva a cabo con la lectura, y es en el transcurso de esta interacción cuando los lectores hacen (y dan sentido) a los textos a la vez que los textos hacen (y dan sentido) a los lectores. En plural. Porque si no hay textos aislados, sino sólo intertextos, tampoco hay lectores aislados, sino sólo... ¿interlectores?

Yo, así como Ud., supongo, no decidí aprender a leer. Me enseñaron, no más. A mí y a todos los de mi generación. Y nos costó unos añitos aprender a hacerlo con cierta fluidez. Tampoco decidí adquirir el hábito de la lectura. Había libros, por ahí. Al leer las palabras que contenían en su interior (bajo la mirada complacida de algunos adultos y la perpleja de algunos otros), uno descubría que decían cosas y contaban historias interesantes, bellas, asombrosas. Caí en ello poco a poco y ya es parte de lo que soy. Pero sólo sigo la estela de, participo en y me lanzo hacia otras innumerables lecturas. Si bien se mira, es la cultura en que integro y que me integra la que lee y se lee, escribe y se escribe.

Así que podemos llevarnos a la cumbre de algún monte, si queremos, como lo hizo Petrarca, nuestro bonito ejemplar de bolsillo de Las confesiones para leer algún pasaje inspirador. El trabajo de los que editaron y fabricaron el libro, el trabajo del hombre que lo escribió (y de cuya autoría no dudaremos ni un instante), el trabajo de aquellos cuyas obras Agustín leyó (¿en voz alta?), comentó, criticó, el trabajo de los desconocidos que preservaron de las injurias del tiempo y del olvido el texto agustiniano (y su lengua, y su enciclopedia), el trabajo de todos nuestros enseñantes y de todos los intérpretes que nos han aconsejado y desafiado y que han orientado nuestra lectura, el trabajo que suponemos realizarán aquellos a quienes nos dirigimos (queridos amigos): todo eso irá con nosotros. Ni ahí arriba vamos a estar solos. 


\section{REFERENCIAS BIBLIOGRÁFICAS}

BARTHES, R. y COMPAGNON, A. (1979). "Lettura". En Enciclopedia Einaudi, vol. 8, 176-199. Turín: Einaudi.

CASSANY, D. (2006). Tras las líneas. Sobre la lectura contemporánea. Barcelona: Anagrama.

CAVALLO, G. y CHARTIER, R. (eds.) (2009 [1995]). Storia della lettura nel mondo occidentale. Trad. de M. Maniaci. Bari-Roma: Laterza. CHARTIER, R. (1995). "Lettura e lettori «popolari» dal rinascimento al settecento". En Storia della lettura nel mondo occidentale, Cavallo y Chartier (eds.), 317-335. Bari-Roma: Laterza.

ECO, U. (1979). Lector in fabula. Milán: Bompiani.

FOUCAULT, M. (2011 [1970]). El orden del discurso. Trad. de A. González Troyano. Barcelona: Tusquets.

GILMONT, J.-F. (2006 [2004]). Dalmanoscritto all'ipertesto. Introduzione alla storia del libro e della lettura. Trad. de L. Rivali. Milán: Le Monnier.

GONZÁLEZ DE ÁVILA, M. (2016). “Leer desde el cuerpo. Una semiótica fenomenológica de la lectura". Signa. Revista de la Asociación Española de Semiótica 25, 631-659.

GREIMAS, A. J. y COURTÉS, J. (1990). Semiótica. Diccionario razonado de la teoría del lenguaje. Ed. española de E. Ballón Aguirre y $\mathrm{H}$. Campodónico Carrión. Madrid: Gredos.

GUBERN, R. (2010). Metamorfosis de la lectura. Edición digital: Titivillus.

LAMPIS, M. (2013). Tratado de semiótica sistémica. Sevilla: Alfar.

LOTMAN, I. M. (1998 [1973]). "Sobre los dos modelos de la comunicación en el sistema de la cultura". En La semiosfera II. Semiótica de la cultura, del texto, de la conducta y del espacio, 42-62. Trad. de D. Navarro. Madrid: Cátedra.

MANGUEL, A. (2014 [1996]). Una historia de la lectura. Trad. de E. Hojman. Buenos Aires: Siglo XXI. 
PARKES, M. (1995). "Leggere, scrivere, interpretare il testo: pratiche monastiche nell'alto medioevo". En Storia della lettura nel mondo occidentale, Cavallo y Chartier (eds.), 71-90. Bari-Roma: Laterza.

PETRUCCI, A. (1995). "Leggere per leggere: un avvenire per la lettura". En Storia della lettura nel mondo occidentale, Cavallo y Chartier (eds.), 411-437. Bari-Roma: Laterza.

SINI, C. (2012). Il sapere dei segni. Filosofia e semiotica. Milán: Jaca Books.

SONTAG, S. (1984 [1964]). “Contra la interpretación”. En Contra la interpretación y otros ensayos, 15-27. Trad. de H. Vázquez Rial. Barcelona: Seix Barral.

Recibido el 1 de marzo de 2018.

Aceptado el 6 de septiembre de 2018. 